\section{P027 \\ TEICOPLANIN: EVALUATION OF SERUM CONCENTRATIONS}

Ibrahim Vhora, Andrew Taylor. Alder Hey Children's Hospital, Liverpool

10.1136/archdischild-2019-nppc.37

Aim The trust has implemented the use of therapeutic drug monitoring (TDM) of teicoplanin on intensive care following research that identified great variability in population pharmacokinetics in children. ${ }^{1-3}$ The summary of the research available showed that patients are not achieving target concentrations. This retrospective audit aimed to evaluate whether patients were achieving target serum concentrations. It also evaluated whether teicoplanin TDM was correctly completed for each patient. The following objectives were set based on grey literature and the Summary of Product Characteristics: ${ }^{4}$ Evaluate if serum concentrations are being taken on or after day 4 post initiation (steady state), and within 1 hour pre-dose (trough) Assess if serum concentrations reach target concentration with standard initial BNFC dosing appropriate for the indication of treatment.

Methods A retrospective report of teicoplanin serum concentrations was provided by the biochemistry labs covering a 6 month period. This report was used to identify the patients for the audit. For each patient: dose information, times and clinical particulars were obtained via the electronic prescribing system, Meditech version 6. If needed, clinical records were obtained from the medical records archive.

Results 71 serum concentrations were identified. 11 were excluded due to unobtainable or incomplete data. Serum concentrations were then evaluated for accuracy. The criteria set for determining accuracy were: Serum concentration taken on or after day 4 post initiation (steady state) Serum concentration taken within 1 hour pre dose (trough) Patient prescribed correct BNFC dosing regimen 55\% $(n=33)$ of patients had all 3 criteria met for an accurate concentration to be determined. This meant $45 \%$ of our patients serum concentrations could not be used to accurately evaluate if current dosing regimens promptly achieve target concentrations. Using the patients' serum concentrations that followed the above criteria, it was found that $64 \%$ of these patients did not reach their desired target concentration. This included patients with: endocarditis $(n=5)$ - aiming for trough greater than $30 \mathrm{mg} / \mathrm{L}$ cystic fibrosis $(n=1)$ - aiming for trough greater than $20 \mathrm{mg} / \mathrm{L}$ other infections such as sepsis $(n=27)$ - aiming for trough greater than $15 \mathrm{mg} / \mathrm{L}$ No patient included in this audit that required a higher target concentration reached their target before the first serum concentration.

Conclusion It is evident that teicoplanin TDM, which is still in its infancy at the trust, requires further support to improve practice. From the serum concentrations that were carried out correctly, this audit begins to illustrate a number of issues surrounding teicoplanin dosing in paediatric patients, especially those with difficult to treat infections. Further research is required to assess how these correlate to clinical outcome in practice as well as evaluating patients not in an intensive care setting. This study can be a driving force for a larger scale study to be carried out so that recommendations can be established and a change of practice can be implemented.

\section{REFERENCES}

1. Ramos-Martín V, Paulus S, Siner S, et al. Population Pharmacokinetics of Teicoplanin in Children. J Antimicrob. Chemother 2014;58: 6920-6927
2. Harding I, Macgowan AP, White LO, et al. Teicoplanin therapy for Staphylococcus aureus septicaemia: relationship between pre-dose serum concentrations and outcome. J. Antimicrob. Chemother 2000;45:835-841.

3. Reed MD, Yamashita TS, Myers CM, et al. The pharmacokinetics of teicoplanin in infants and children. J. Antimicrob. Chemother 1997;39:789-796.

4. Targocid 400mg [Internet]. Targocid $400 \mathrm{mg}$ - Summary of Product Characteristics (SmPC) - (eMC). Available from: https://www.medicines.org.uk/emc/product/2927 (Accessed 20 February 2018)

\section{P028 AUDIT OF SODIUM BLOOD LEVELS IN PATIENTS ON PICU RECEIVING HEPARIN IN SODIUM CHLORIDE $0.9 \%$ COMPARED TO HEPARIN IN SODIUM CHLORIDE $0.45 \%$}

Sophie Jeffery, Lauren Jane Hutchinson, Jenny Gray, Anna Roberts. University Hospitals Bristol NHS Foundation Trust

\subsection{6/archdischild-2019-nppc.38}

Background On our paediatric intensive care unit (PICU), we have historically used heparin in $0.9 \%$ sodium chloride as a continuous flush to maintain patency of arterial and central venous pressure (CVP) central lines. Practice varies across the UK, some units use heparin in sodium chloride whilst others use sodium chloride alone to maintain line patency. Currently in paediatrics there is not enough evidence to change local practice by removing heparin from the flushes. ${ }^{1}$ A cost saving scheme was identified whereby using heparin in sodium chloride $0.45 \%$ was cheaper than using heparin in sodium chloride $0.9 \%$ (both products from Baxter). A proposal was put together and approved by the PICU quality improvement group, demonstrating that in theory, there should be no significant loss of sodium to patients due to the change in fluids. Although it may seem that flushes would not contribute a large proportion of a patient's fluid requirement, in a typical $2.5 \mathrm{~kg}$ patient post cardiac surgery, $2 \mathrm{ml} /$ hour would actually provide $40 \%$ of the patient's total fluid allowance. This change in practice was implemented in June 2018.

Aim The aim of this audit was to establish whether patients receiving heparin in sodium chloride $0.45 \%$ had lower sodium blood levels or a greater drop in sodium levels than patients on heparin in sodium chloride $0.9 \%$. We also evaluated whether a higher incidence of line blockage was reported in either group.

Methods Data was collected retrospectively using the Phillips ICCA electronic prescribing system, using 25 patients pre (April 2018) and 25 patients post (June and July 2018) implementation of the heparin in sodium chloride $0.45 \%$ flushes. Sodium blood gas levels were used as these were more consistently taken than plasma blood samples.

Results The data showed that heparin in sodium chloride $0.45 \%$ did not reduce sodium levels in patients. In each group 1 patient required additional sodium supplementation and 2 patients' lines became blocked and therefore were removed. The average sodium on admission in the heparin in sodium chloride $0.9 \%$ group was $139.96 \mathrm{mmol} / \mathrm{L}$ (CI 95\% \pm 1.17 $\mathrm{mmol} / \mathrm{L}$ ) compared to the heparin in sodium chloride $0.45 \%$ group which was $135.68 \mathrm{mmol} / \mathrm{L}$ (CI $95 \% \pm 1.91 \mathrm{mmol} / \mathrm{L}$ ). The average sodium level on either line removal or discharge from PICU was $138 \mathrm{mmol} / \mathrm{L}(\mathrm{CI} 95 \% \pm 1.35 \mathrm{mmol} / \mathrm{L}$ ) in the heparin sodium chloride $0.9 \%$ group compared to 135.72 $\mathrm{mmol} / \mathrm{L}(\mathrm{CI} 95 \% \pm 1.88 \mathrm{mmol} / \mathrm{L})$ in the heparin sodium chloride $0.45 \%$ group. The results indicated that patients within the pre-change group lost, on average, $2 \mathrm{mmol} / \mathrm{L}$ sodium compared to their admission sodium levels compared to $0.04 \mathrm{mmol} / \mathrm{L}$ in the post-change group. The reason for this 